\title{
Campylobacter enterocolitis: general and surgical aspects
}

\author{
David P. Sellu \\ Department of Surgery, Dudley Road Hospital, Birmingham B18 7QH, UK.
}

\section{Introduction}

Bacteria of the Campylobacter genus have long been known to be pathogens to animals but only recently as a leading cause of enterocolitis in man. The spectrum of illnesses produced by this group of organisms is broad, and the patients may often present to the surgeon. It seems timely, therefore, to review the historical background of the organism, its biological, epidemiological and other properties, and the clinical features of the infections it causes, with a discussion on those aspects which are of particular interest to the surgeon.

\section{Historical background}

Bacteria of the genus Campylobacter have been known to cause abortion and diarrhoea in cattle and sheep since they were first isolated (MacFadyean \& Stockman, 1909). Because of their striking morphological similarity to Vibrio cholerae, they were classified as members of the Vibrio genus and the type species now known as Campylobacter fetus (see below) was called Vibrio fetus. The term 'campylobacter', which is derived from two Greek words meaning 'curved rod', was first proposed by Sebald \& Veron in 1963 as a generic name for these organisms on the grounds that they differed from the classical cholera and halophilic groups in many important respects.

Elizabeth King (1957 \& 1962) was the first to study human strains in detail. She realized that while some of these conformed to the classic type, others formed a similar but distinct group which she provisionally called 'related vibrios'. She established the difference between the two species of Vibrio from two characteristics. First, the optimal growth temperature for culture of the related vibrio is $42^{\circ} \mathrm{C}$, whereas Vibrio fetus does not grow at this temperature. Second, the

Correspondence: D.P. Sellu, Ch.M., F.R.C.S.

Accepted: 13 February 1986 serological properties of the two strains were distinctly different.

Human infections have been recognized since 1947 (Vinzent et al., 1947), although they have been infrequently reported until recent years. In those early years the organisms were isolated from blood, cerebrospinal fluid and other body fluids, and from abscesses (Bokkenheuser, 1970). For, although the patients presented mainly with gastrointestinal symptoms, attempts to culture the organisms from faeces were unsuccessful because of overgrowth by coliforms.

Two important coproculture methods have been used to overcome the problem of contamination of faecal specimens by coliforms. The first was reported by Cooper \& Slee (1971) and by Slee (1972) in Australia who noted that a campylobacter isolated from the blood culture of a patient with diarrhoea was resistant to cephalothin. Cephalothin discs were therefore applied to the surface of a blood agar plate innoculated with the patient's faeces. Following incubation under microaerophilic conditions (of greatly reduced oxygen tension), campylobacter colonies were noted in the zone of the cephalothin disc. The second method was introduced by Dekeyser and colleagues (1972) in Brussels in 1969 and was based on the fact that campylobacters are small enough to pass through a filter that holds back the other organisms. Using this method they isolated campylobacters from the stools of $5.1 \%$ of children with diarrhoea and $1.3 \%$ of children without diarrhoea.

These discoveries received little attention until 1977 when Skirrow, a microbiologist at Worcester Royal Infirmary in England, described a method for isolating campylobacters from stools that eliminated the need to use the rather tedious filtration technique. In his method (Skirrow, 1977) stools were directly innoculated on to a selective culture medium containing the antibiotics vancomycin, polymyxin $B$, and trimethoprim, and incubated at $43^{\circ} \mathrm{C}$ in an atmosphere 
of $5 \%$ oxygen, $10 \%$ carbon dioxide, and $85 \%$ nitrogen. Skirrow examined the stools of 803 patients with diarrhoea and found that campylobacters were the most common enteric organisms cultured, more common even than salmonella, shigella, and enteropathic Escherichia coli. He predicted that campylobacter would prove to be the commonest identifiable cause of infectious diarrhoea. Many reports from other parts of the United Kingdom (Kendall \& Tanner, 1982; Bruce et al., 1977; Dale, 1977; Pearson et al., 1977; Telfer Brunton \& Heggie, 1977; Anonymous, 1978), the continent of Europe (Lindquist $e t$ al., 1978; Severin, 1978; Muytjens \& van Dis, 1978), Canada (Karmali \& Fleming, 1979; Kalnins \& Jackson, 1977), United States of America (Drake et al., 1981; Blaser \& Barth Reller, 1981), and Africa (De Mol \& Bosmans, 1978) have confirmed this prediction. The campylobacters are, therefore, an important cause of disease worldwide.

\section{The campylobacters}

Campylobacters are small, curved, S-shaped or spiral, motile Gram-negative rods. They are microaerophilic, being neither truly anaerobic nor aerobic, but requiring an environment of reduced oxygen tension for optimal growth. Failure to appreciate this point was in part responsible for the delay in recognizing this organism as a human pathogen. They neither oxidize nor ferment carbohydrates. Veron \& Chatelain (1973) proposed a scheme which, with slight modification, is now widely used for classifying these organisms. Five species of the genus Campylobacter are recognized: $C$. fetus, $C$. jejuni, $C$. coli, $C$. fecalis and $C$. sputorum. Two of these, C. fetus and C. sputorum have subspecies which have been characterized: for the former they are subspecies (ss) fetus and ss veneralis, and for the latter ss sputorum, ss bulbus and ss mucosalis. Classic Vibrio fetus now becomes $C$. fetus, and King's related vibrios $C$. jejuni and $C$. coli. As these latter two species of organism differ only slightly in phenotypic characteristics (Skirrow \& Benjamin, 1980), and C. jejuni is a more common pathogen, they are often collectively referred to as $C$. jejuni. If the subspecies to which the organism belongs is known, the organism will be described by its genus name, followed by its species and subspecies name, for instance, $C$. fetus ss veneralis. At the present time only $C$. jejuni and $C$. fetus ss fetus are known to cause disease in man. In the laboratory the organisms are recognized by their physical properties on light microscopy, and are cultured using a selective culture medium (usually Skirrow's medium) and incubated at $42^{\circ} \mathrm{C}$ in a microaerophilic environment, as described earlier.

\section{Epidemiology}

Birds, especially chicken and turkeys, are a common reservoir for $C$. jejuni. Wild birds also carry the organism. In nearly all the birds the excretion of the organism is not associated with disease. It has been demonstrated that $C$. jejuni can survive the commercial processing procedure to which chickens and turkeys are subjected and this source must therefore be recognized as important in the spread of infection (Simmons \& Gibbs, 1979).

Mammals are also an important source of the organism. $C$. jejuni has been isolated from healthy pigs, cattle, horses and sheep, and in some of these animals the organism may cause an illness with diarrhoea as a prominent symptom. Turnbull \& Rose (1982) have reported on the examination of over 6,000 raw red meat samples from retail and other outlets: $C$. jejuni was isolated from $1.6 \%$ and the workers concluded that contamination of meats by this organism was in general very low. Household dogs and cats are commonly infected, and are known to be a source of infection causing diarrhoea in man (Blaser et al., 1981a). Humans, both infected and symptomless carriers, may be a common source of environmental contamination.

Fresh water (Blaser et al., 1980a) and unpasteurized or incompletely pasteurized milk (Robinson \& Jones, 1981) are important external sources of $C$. jejuni: the organism has been cultured from fresh water in which it has been shown to survive for up to four weeks.

Transmission of $C$. jejuni is almost certainly by the faecal-oral route by ingestion of contaminated food, water or milk (Pearson et al., 1983). One boys' boarding school in Sussex experienced a major epidemic attributable to unpasteurized milk (Pearson et al., 1983), and in another in Essex, 257 cases of campylobacter gastroenteritis were almost certainly due to drinking water from an unchlorinated uncovered storage tank supplied from a borehole (Palmer et al., 1983). Person-to-person transmission is probably unimportant but it has been reported (Blaser et al., 1981b).

\section{Age and sex distribution}

The infection has been reported in all ages from 2 weeks (Karmali \& Fleming, 1979) to well into the 90s. Infections have also occurred in neonates who have acquired the organisms from their asymptomatic mothers (Karmali \& Tan, 1980). In the study by Karmali \& Fleming (1979) of campylobacter enteritis in patients under the age of 15 years the highest incidence $(20 \%)$ occurred in those below the age of three years. Many of the adult patients were aged 
between 15 and 45 , and slightly more than half of them were men.

\section{Predisposing factors}

Initial reports of campylobacter infections observed that the majority of patients affected had pre-existing illnesses such as alcoholism, cirrhosis of the liver, diabetes mellitus, atherosclerosis, rheumatic heart disease, lymphoma or leukaemia, had had splenectomy or were on immunosuppressive therapy (Rettig, 1979). More recent studies of both outbreaks and sporadic infections have established that the vast majority of persons affected have been previously healthy. The latter represents the true state of affairs, now that Campylobacter is widely recognized as a human pathogen and is looked for more frequently in the investigation of diarrhoea.

\section{Pathogenesis}

\section{Gastrointestinal involvement}

C. jejuni is primarily a gastrointestinal pathogen, but may affect other organs and systems. The high prevalence of this organism in asymptomatic carriers and in patients with only mild illness suggests that it is not as infective as other gastrointestinal pathogens such as salmonella or shigella.

There is debate about the incubation period of this infection but it is believed to be from one to 7 days (mean 4 days). Many organisms are destroyed by the acid environment of the stomach but those that reach the small bowel are liable to survive and multiply; the $\mathrm{pH}$ and the microaerophilic medium of the small bowel are more favourable. The drug cimetidine, now used widely in the treatment of peptic ulcers, lowers gastric acidity, and it has been suggested that in patients on this medication a relatively small inoculum of the organism may establish infection (Blaser et al., 1980a; Chandra et al., 1982). Organisms are excreted into the large bowel where they are also liable to multiply further.

\section{Sites affected in the gastrointestinal tract}

The sites in the gastrointestinal tract most liable to sustain injury are the jejunum, ileum, and colon and rectum, but other sites may be affected.

Bentley et al. (1985) observed acute gingivostomatitis and glossitis in a child with campylobacter colitis. An organism which, by light microscopy resembles $C$. jejuni, has been cultured from the gastric mucosa of patients with an active form of chronic gastritis, and may well be a cause of this condition
(Warren \& Marshall, 1983). Acute appendicitis developing during the course of acute colitis due to $C$. jejuni is well recognized (Sellu \& Lynn, 1985).

\section{Macroscopic and microscopic changes}

Information on the pathological changes observed during the course of this infection have come from laparotomy, sigmoidoscopy and colonoscopy, from post-mortem examinations carried out on patients who have succumbed from the disease, and from animal experiments. It is not clear whether the organism produces mucosal damage by direct invasion or by enterotoxin production (Butzler \& Skirrow, 1979). The pathological features depend on the severity of the injury: at one extreme there may be no gross changes when the bowel is inspected from the serosal aspect (Ponka et al., 1981; Lambert, J.R. et al., 1979), and at the other there may be inflammation and oedema of the full thickness of the bowel wall (Skirrow, 1977), haemorrhagic lesions (King, 1962), or even frank necrosis (Evans \& Dadswell, 1967), gangrene (Sellu \& Lynn, 1985) and perforation (Stephenson \& Cotton, 1985). When the bowel is viewed from the mucosal aspect, more consistent changes are likely to be found. These include the presence of mucus, pus and blood in the lumen of the bowel, and a haemorrhagic, oedematous and friable mucosa, which cannot be distinguished from ulcerative colitis (Lambert, J.R. et al., 1979; Lambert, M.E. et al., 1979; Blaser et al., 1980b). Segmental mucosal oedema, loss of vascular pattern with ulceration, linear clefts and a cobblestone appearance identical to those of Crohn's disease have also been described (Loss et al., 1980). As with ulcerative colitis, the rectum has been found to be involved in practically all patients from whose stools C. jejuni has been isolated (Price et al., 1979).

Histological examination of mucosal biopsy from infected patients has shown nonspecific colitis with flattening of the surface epithelium and depletion of goblet cells. The crypt walls are infiltrated by polymorphonuclear leucocytes, and numerous crypt abscesses are present. There is a mixed inflammatory infiltrate in the lamina propria comprising polymorphs and plasma cells (Willoughby et al., 1979). These changes have been interpreted as being consistent with Crohn's disease or ulcerative colitis (Lambert, M.E. et al., 1979; Blaser et al., 1980b; Willoughby et al., 1979). In some cases the appearances have been similar to those described for salmonella and shigella, and different from those of typical ulcerative colitis or Crohn's disease (Price et al., 1979).

Involvement of organs outside the gastrointestinal tract

Biliary tract Darling et al. (1979) have described three cases of cholecystitis in which $C$. jejuni was isolated 
from bile. Two of the patients were operated upon during the acute phase of the illness and the third electively. Cholecystitis due to this organism has been described by other workers (Mertens \& De Smet, 1979).

Blood stream infection Bacteraemia and septicaemia developing in the course of colitis by $C$. jejuni is now well documented. In one case (Longfield et al., 1979), organisms were found in the blood stream during the acute phase of the illness and also during convalescence. Guerrant et al. (1978) have reviewed 91 cases of blood stream infections: while the organism was believed to have originated from the gastrointestinal tract in the majority of patients, there was evidence to implicate other portals of entry such as skin, female genital tract and lung.

Urinary tract Urinary tract infections with campylobacter have been described (Davies \& Penfold, 1979).

Skin and joints Reactive (Kosunen et al., 1980) and purulent (Guerrant et al., 1978) arthritis and erythema nodosum (Ellis et al., 1982) have also been reported.

Others Other infections due to campylobacter include meningitis, empyema thoracis, pustules, endocarditis and placental infection (Guerrant et al., 1978), septic thrombophlebitis in a patient with Hodgkin's disease (Geffen et al., 1983) and bilateral deep venous thrombophlebitis (Vesely et al., 1975). Mycotic aneurysms of the abdominal aorta caused by campylobacter (Anolik et al., 1983; Blabey et al., 1983), or pre-existing aortic aneurysms infected by this organism (Marty et al., 1983) have been documented.

\section{Symptoms and signs}

Many of the features of campylobacter infections are identical to those of other gastrointestinal infections. In many other cases the clinical symptoms and signs may be similar to those of intra-abdominal diseases other than those due to enterocolitis. The illness may be mild with few, if any, gastrointestinal symptoms, on the one hand, or it may present with diarrhoea and severe abdominal pain, on the other. Diarrhoea may present late in the course of the illness or not at all, and the illness may mimic other diseases.

Following ingestion of the organism there is a prodromal illness consisting of malaise, nausea, anorexia and fever lasting for a day or two. Colicky abdominal pains, muscle pains, backache and other joint pains may be experienced.

Diarrhoea and abdominal pain, when present, will dominate the clinical picture. The diarrhoea begins gradually in some and explosively in others; in all cases faeces become watery, offensive and often bilestained. Later the faeces become mixed with blood, mucus and pus, and the characteristics will then be those of inflammatory bowel disease such as acute ulcerative colitis. Diarrhoea often lasts for 3 to 4 days, and the stools gradually become solid in most cases. Recovery may be slow in a minority of patients in whom diarrhoea may persist for several weeks. Abdominal pain may be constant or colicky and may occur in any quadrant of the abdomen, but most frequently occurs on the right. Nausea and vomiting are common but dehydration less so. A low-grade fever is common and rigors may occasionally occur. The abdomen is often mildly tender but severe tenderness, muscle guarding and rebound tenderness are sometimes present. Bowel sounds are often normal but may be increased or absent.

\section{Why campylobacter enterocolitis sometimes presents to the surgeon}

Campylobacter colitis can present to the surgeon for several reasons, the most common of which are: (a) It can mimic intra-abdominal surgical emergencies such as intestinal obstruction, appendicitis, and cholecystitis (Ponka et al., 1981); the diagnosis is hampered by the late onset or even total absence of diarrhoea, and some of these patients have undergone unnecessary operations. A patient who had spontaneous bacterial peritonitis due to infection with Campylobacter jejuni has been described (McNeil et al., 1984); this complication was secondary to alcoholic cirrhosis, a condition in which spontaneous bacterial peritonitis is well known to occur (Conn \& Fessel, 1971). (b) It may resemble Crohn's disease or acute ulcerative colitis. One patient who was known to have ulcerative colitis presented with diarrhoea which was thought to be due to relapse of ulcerative colitis, but proved later to be due to campylobacter colitis (Chandra et al., 1982). It is important, therefore, that infection is excluded in 'relapses' of inflammatory bowel disease. (c) It can present together with a true 'surgical' condition such as acute appendicitis (Sellu \& Lynn, 1985), cholecystitis (Darling et al., 1979; Mertens \& De Smet, 1979), or mesenteric lymphadenitis (Skirrow, 1977). (d) Campylobacter colitis may be complicated by toxic megacolon (McKinley et al., 1980; Kalkay et al., 1983; Stephenson \& Cotton, 1985), massive lower gastrointestinal bleeding (Michalak et al., 1980), and bowel necrosis (Evans \& Dadswell, 1967). In one of the patients with toxic megacolon two large bowel perforations occurred and the patient developed peritonitis (Stephenson \& Cotton, 1985).

The latter two situations indicate that merely because a diagnosis of campylobacter colitis has been 
established, does not mean that a complication requiring operative treatment will not occur.

\section{Diagnosis}

There must be a high index of suspicion of infective enterocolitis when investigating a patient with abdominal pain, with or without diarrhoea. Rectal swabs have sometimes yielded the diagnosis when diarrhoea has been absent (Bentley et al., 1985). Otherwise a fresh specimen of stool must be collected and sent to the laboratory immediately.

\section{Microscopy of stools}

A rapid presumptive diagnosis of campylobacter enteritis can be made during the acute phase of the illness by dark-field or phase-contrast microscopy performed on a fresh specimen of stool. Red cells and neutrophils will also be present in many cases.

\section{Stool culture}

This will enable confirmation of the diagnosis. The genus, species and subspecies of the organism will be determined, as will its antibiotic sensitivities. In severe infections, blood should also be sent for culture.

\section{Serology}

Blood should be sent for serology during the acute phase of the illness and during convalescence 6 weeks later. Specific antibodies which the patients acquire during the illness are tested for. Tube agglutination tests have detected specific agglutinins to a titre of 1:80 or more, and a four-fold or greater rise of titre between acute and convalescent samples has been noted (Skirrow, 1977).

\section{Rectal biopsy}

The possibility of cross infection must be borne in mind when any patient with diarrhoea which may be due to an infective cause is being investigated by sigmoidoscopy and barium enema studies. If adequate precautions are taken, sigmoidoscopy and rectal biopsy may yield useful information. Price and colleagues (1979) performed sigmoidoscopy on 21 out of 29 patients presenting to an infectious disease unit with acute diarrhoea. Rectal biopsies were abnormal in all but four, and in the patients with campylobacter infection there was histologically a characteristic proctocolitis in each case although the rectum was macroscopically normal in some. The abnormalities consisted, in all cases, of oedema producing separation of the crypts and a gap between their base and the muscularis mucosae, and of focal collections of polymorphs. There were isolated crypt abscesses and 'incipient' crypt abscesses in which, according to the authors, the majority of polymorphs lay between the crypt cells and a relatively small number within the lumen; there was partial destruction or flattening of the crypt epithelial cells. These and other histological changes which were described, were different from those of typical ulcerative colitis and Crohn's disease. However, some other workers (Lambert, M.E. et al., 1979; Colgan et al., 1980) have reported that the mucosal changes cannot be distinguished from those of Crohn's disease or ulcerative colitis. One interesting observation is that whatever the original changes on rectal biopsy, they improve markedly in patients with infective diarrhoea during the convalescent period, whereas in those with inflammatory bowel disease they persist (Dickinson et al., 1979).

\section{Barium enema}

The radiological features of campylobacter colitis have not been described in detail, largely because the disease is self limited in many patients. In mild cases there are minimal changes. In more severe disease the changes may affect the colon as well as the ileum (Lambert, J.R. et al., 1979), and consist of ulceration and multiple aphthous ulcers which are similar to those caused by Crohn's disease or ulcerative colitis (Kollitz et al., 1981; Bentley et al., 1985). Barium enema has been valuable in excluding obstruction and hence avoiding an operation in a patient with symptoms and signs and plain X-ray findings suggestive of intestinal obstruction (Bentley et al., 1985).

\section{Treatment}

\section{Conservative management}

Many infections with $C$. jejuni pursue a self-limiting course, and many patients with mild illness will recover completely without specific treatment (Blaser et al., 1979). However, when symptoms are severe and the illness protracted, or when diarrhoea is explosive and bloody, it is wise to administer fluids and specific antimicrobial therapy.

Erythromycin (as the ethylsuccinate, because of its lower risk of hepatitis) is the drug of choice, as most strains of $C$. jejuni are sensitive to it. Other antimicrobial agents to which the organism will often respond include gentamicin, tetracyclines, clindamycin, and chloramphenicol. A premature return to solid foods often precipitates a recurrence of symptoms (Skirrow, 1977), and hence it is advisable to allow only a fluid diet until all symptoms have subsided. Antidiarrhoeal agents such as diphenoxylate hydro- 
chloride (Lomotil) and compounds containing kaolin and morphine should be avoided as they may prolong the course of the diarrhoea.

\section{Operative treatment}

The large number of patients who have undergone unnecessary operations in the course of campylobacter colitis is an indication that an operation is rarely necessary in this condition (Ponka et al., 1981). In some of the cases in which a complication requiring an operation has occurred, such a complication has been potentially life-threatening (Sellu \& Lynn, 1985; Michalak et al., 1980; Stephenson \& Cotton, 1985); death from bowel necrosis has been recorded (Evans \& Dadswell, 1967). From reports of the frequency of campylobacter infections, however, it is reasonable to assume that few patients will need an operation during the course of this illness. There are no studies as yet to show what the indications for surgery should be, or, when an operation is indicated, the timing of it. Much of the advice given here is based on the few reports in the literature and on the author's own experience of this infection.

Laparotomy is indicated if, despite specific antimicrobial treatment, there are features to suggest a complication such as appendicitis or bowel necrosis. If an operation is performed, it is wise to increase the number of antibiotics to include, say, gentamicin and metronidazole, in order to cover other intestinal bacteria. If acute cholecystitis is suspected, the author believes that the patient should be treated conservatively unless the inflammation is not subsiding or there are signs of biliary perforation. If the features are those of large bowel obstruction it may be prudent to request an urgent barium enema examination, as an operation will be avoided if pseudo-obstruction is found (Bentley et al., 1985).

Right hemicolectomy was required in the case of a patient who developed massive gastrointestinal bleeding from multiple mucosal ulcers in the terminal ileum and at the ileo-caecal valve (Michalak et al., 1980). Arteriography was very helpful in defining the otherwise grossly indefinable source of bleeding, and the patient made good recovery from the operation. Another patient who developed toxic megacolon and colonic perforations following campylobacter colitis was successfully treated by subtotal colectomy and ileo-rectal anastomosis (Stephenson \& Cotton, 1985).

If a patient presents with signs of intra-abdominal surgical emergency, campylobacter colitis should be borne in mind as a possible cause. Treatment will depend on the clinical features and the decision to operate should be made as in other patients presenting with acute abdominal pain.

\section{Conclusions}

Campylobacters are a relatively common cause of enterocolitis in man. The clinician to whom the patient presents must have a high index of suspicion of this condition, especially in those patients whose features are atypical. Some of the more severe infections may present to the surgeon, who must balance the risk of missing a lesion for which an operation is mandatoryc against that of an unnecessary operation. A knowledge of the biological behaviour of, and the spectrum of clinical illnesses produced by, this genus of bacteria is essential for rational therapy, and communication between clinicians and microbiologists is vital for the successful outcome of the disease.

\section{References}

ANOLIK, J.R., MILDVAN, D., WINTER, J.W., PUTTLITZ, D., RUBENSTEIN, S.M. \& LOZMAN, H. (1983). Mycotic aortic aneurysm: a complication of $C$. fetus septicemia. Archives of Internal Medicine, 143, 609.

ANONYMOUS (1978). Campylobacter infection in Britain 1977. British Medical Journal, 1, 1357.

BENTLEY, D., LYNN, J. \& LAWS, W.J. (1985). Campylobacter colitis with aphthous ulceration mimicking obstruction. British Medical Journal, 291, 634.

BLABEY, R.G. JR, PARRY, M.F., BULL, S.M. \& WEED, C.B. (1983). Mycotic aneurysm of the abdominal aorta: successful management of the $C$. fetus aortitis. Connecticut Medicine, 47, 129.

BLASER, M.J., BERKOWITZ, I.D., LAFORCE, F.M., RELLER, L.B. \& WANG, W-L.L. (1979). Campylobacter enteritis: clinical and epidemiological features. Annals of Internal Medicine, 91, 179.

BLASER, M., HARDESTY, H.L., POWERS, B. \& WANG, W-L.L.

(1980a). Survival of Campylobacter fetus subsp. jejuni in biological milieus. Journal of Clinical Microbiology, 11, 309.

BLASER, M.J., PARSONS, R.B. \& WANG, W-L.L. (1980b). Acute colitis caused by Campylobacter fetus ss. jejuni. Gastroenterology, 78, 448.

BLASER, M.J. \& BARTH RELLER, L. (1981). Campylobacter enteritis. New England Journal of Medicine, 305, 1444.

BLASER, M., CRAVENS, J., POWERS, B.W. \& WANG, W.L. (1981a). Campylobacter enteritis associated with canine infection. Lancet, i, 979.

BLASER, M.J., WALDMAN, R.J., BARRETT, T. \& ERLANDSON, A.L. (1981b). Outbreaks of campylobacter enteritis in two extended families: evidence for person to person transmission. Journal of Pediatrics, 98, 254.

BOKKENHEUSER, V. (1970). Vibrio fetus infection man, I. Ten new cases and some epidemiologic observations. American Journal of Epidemiology, 91, 400. 
BRUCE, D., ZOCHOWSKI, W. \& FERGUSON, I.R. (1977). Campylobacter enteritis (letter). British Medical Journal, 2, 1219.

BUTZLER, J.P. \& SKIRROW, M.B. (1979). Campylobacter enteritis. Clinics in Gastroenterology, 18, 737.

CHANDRA, L., BARROWMAN, J.A., KUTTY, K.P. \& FARDY, P. (1982). Campylobacter infection mimicking relapse of ulcerative colitis. Canadian Medical Association Journal, 126, 389.

COLGAN, T., LAMBERT, J.R., NEWMAN, A. \& LUK, S.C. (1980). Campylobacter jejuni enterocolitis: a clinicopathologic study. Archives of Pathology and Laboratory Medicine, (Chicago), 104, 571.

CONN, H.O. \& FESSEL, J.M. (1971). Spontaneous bacterial peritonitis in cirrhosis: variations on a theme. Medicine, SO, 161.

COOPER, I.A. \& SLEE, K.J. (1971). Human infection by Vibrio fetus. Medical Journal of Australia, 1, 1263.

DALE, B. (1977). Campylobacter enteritis (letter). British Medical Journal, 2, 318.

DARLING, W.M., PEEL, R.N., SKIRROW, M.B. \& MULIRA, A.E.J.L. (1979). Campylobacter cholecystitis. Lancet, i, 1302.

DAVIES, J.S. \& PENFOLD, J.B. (1979). Campylobacter urinary infection. Lancet, i, 1091.

DEKEYSER, P., GOUSUIN-DETRAIN, M., BUTZLER, J.P. \& STERNON, J. (1972). Acute enteritis due to related vibrio: first positive stool cultures. Journal of Infectious Diseases, $125,390$.

De MOL, P. \& BOSMANS, E. (1978). Campylobacter enteritis in Central Africa. Lancet, i, 604.

DICKINSON, R.J., GILMOUR, H.M. \& MCCLELLAND, D.B.L. (1979). Rectal biopsy in patients presenting to an infectious disease unit with diarrhoeal disease. Gut, 20, 141.

DRAKE, A.A., GILCHRIST, M.J.R., WASHINGTON, J.A., II, HUIZENGA, K.A. \& BAN SCOY, R.E. (1981). Diarrhea due to Campylobacter fetus subspecies jejuni: a clinical review of 63 cases. Mayo Clinic Proceedings, 56, 414.

ELLIS, M.E., POPE, J., MOKASHI, A. \& BUNBAR, E. (1982). Campylobacter colitis associated with erythema nodosum. British Medical Journal, 285, 937.

EVANS, R.G. \& DADSWELL, J.V. (1967). Human vibriosis. British Medical Journal, 3, 240.

GEFFEN, D.B., GILL, V.J. \& CHABNER, B.A. (1983). Campylobacter thrombophlebitis. Annals of Internal Medicine, 99, 126.

GUERRANT, R.L., LAHITA, R.G., WINN, W.C. \& ROBERTS, R.B. (1978). Campylobacteriosis in man: pathogenic mechanisms and review of 91 blood stream infections. American Journal of Medicine, 65, 584.

KALKAY, M.N., AYANIAN, Z.S., LEHAF, E.A. \& BALDI, A. (1983). Campylobacter-induced toxic megacolon. American Journal of Gastroenterology, 78, 557.

KALNINS, I. \& JACKSON, A.W. (1977). Isolation of Campylobacter fetus ss. jejuni in Canada. Canadian Diseases Weekly Report, 50, 198.

KARMALI, M.A. \& FLEMING, P.C. (1979). Campylobacter enteritis in children. Journal of Pediatrics, 94, 527.

KARMALI, M.A. \& TAN, Y.C. (1980). Neonatal campylobacter enteritis. Canadian Medical Association Journal, 122, 192.

KENDALL, E.J.C. \& TANNER, E.I. (1982). Campylobacter enteritis in general practice. Journal of Hygiene, Cam- bridge, 88, 155.

KING, E.O. (1957). Human infections with Vibrio fetus and a closely related vibrio. Journal of Infectious Diseases, 101, 119.

KING, E.O. (1962). The laboratory recognition of Vibrio fetus and a closely related vibrio isolated from cases of human vibriosis. Annals of the New York Academy of Sciences, 98, 700.

KOLLITZ, J.P.M., DAVIS, G.B. \& BERK, R.N. (1981). Campylobacter colitis: a common infectious form of acute colitis. Gastrointestinal Radiology, 6, 227.

KOSUNEN, T.U., KAURANEN, O. \& MARTIO, J. (1980). Reactive arthritis after Campylobacter jejuni enteritis in patients with HLA-B27. Lancet, i, 1312.

LAMBERT, J.R., TISCHLER, M.E., KARMALI, M.A. \& NEWMAN, A. (1979). Campylobacter ileocolitis: an inflammatory bowel disease. Canadian Medical Association Journal, 121, 1377.

LAMBERT, M.E., SCHOFIELD, P.F., IRONSIDE, A.G. \& MANDAL, B.K. (1979). Campylobacter colitis. British Medical Journal, 1, 857.

LINDQUIST, B., KJELLANDER, J. \& KOSUNEN, T. (1978). Campylobacter enteritis in Sweden (letter). British Medical Journal, 1, 303.

LONGFIELD, R., O'DONNELL, J., YUDT, W., LISSNER, C. \& BURNS, T. (1979). Acute colitis and bacteremia due to Campylobacter fetus. Digestive Diseases and Sciences, 24, 950.

LOSS, W.L., MAGALA, J.C. \& PEREIRA, M. (1980). Campylobacter colitis presenting as inflammatory bowel disease with segmental colonic ulcerations. Gastroenterology, 79, 138.

MACFADYEAN, F. \& STOCKMAN, S. (1909). Report of the Departmental Committee Appointed by the Board of Agriculture and Fisheries to Inquire into Epizootic Abortion, volume 3. His Majesty's Stationery Office: London.

MARTY, A.T., WEBB, T.A., STUBBS, A.G. \& PENKAVA, R.R. (1983). Inflammatory abdominal aortic aneurysm infected by $C$. fetus. Journal of the American Medical Association, 249, 1190.

MCKINLEY, M.J., TAYLOR, M. \& SANGREE, M.H. (1980). Toxic megacolon with campylobacter colitis. Connecticut Medicine, 44, 396.

McNEIL, N.I., BUTTOO, S. \& RIDGWAY, G.L. (1984). Spontaneous bacterial peritonitis due to Campylobacter jejuni. Postgraduate Medical Journal, 60, 487.

MERTENS, A. \& De SMET, M. (1979). Campylobacter cholecystitis. Lancet, i, 1092.

MICHALAK, D.M., PERRAULT, J., GILCHRIST, M.J., DOZOIS, R.R., CARNEY, J.A. \& SHEEDY, P.F., II. (1980). Campylobacter fetus ss. jejuni: a cause of massive lower gastrointestinal hemorrhage. Gastroenterology, 79, 742.

MUYTJENS, H.L. \& VAN DIS, P. (1978). Campylobacter fetus subspecies jejuni als verwekker van diarree. Nederlands Tijdschrift voor Geneeskunde, 122, 504.

PALMER, S.R., GULLY, P.R., WHITE, J.M., PEARSON, A.D., SUCKLING, W.G., JONES, D.M., RANES J.C.L. \& PENNER, J.L. (1983). Water-borne outbreak of campylobacter gastroenteritis. Lancet, i, 287.

PEARSON, A.D., SKIRROW, M.B., ROWE, J., DAVIES, J. \& JONES, D.M. (Editors). (1983). Campylobacter II: Proceedings of the Second International Workshop on Campylobacter Infections. Public Health Laboratory Service: London. 
PEARSON, A.D., SUCKLING, W.G., RICARDI, I.D., KNILL, M., WARE, E. (1977). Campylobacter-associated diarrhoea in Southampton (letter). British Medical Journal, 2, 955.

PONKA, A., PITKANEN, T. \& KOSUNEN, T.U. (1981). Campylobacter enteritis mimicking acute abdominal emergency. Acta Chirurgica Scandinavica, 147, 663.

PRICE, A.B., JEWKES, J. \& SANDERSON, P.J. (1979). Acute diarrhoea: campylobacter colitis and the role of rectal biopsy. Journal of Clinical Pathology, 32, 990.

RETTIG, P.J. (1979). Medical progress: campylobacter infections in human beings. Journal of Pediatrics, 94, 855.

ROBINSON, D.A. \& JONES, D. (1981). Milk-borne campylobacter infection. British Medical Journal, 282, 1374.

SEBALD, M. \& VERON, M. (1963). Teneur en bases de l'ADN et classification des vibrions. Annales de l'Institut Pasteur, $105,897$.

SELLU, D.P. \& LYNN, J.A. (1985). Campylobacter colitis associated with appendicitis and septicaemia. British Medical Journal, 291, 1688.

SEVERIN, W.P. (1978). Campylobacter en enteritis. Nederlands Tijdschrift voor Geneeskunde, 122, 499.

SIMMONS, N.A. \& GIBBS, F.J. (1979). Campylobacter spp. in oven-ready poultry. Journal of Infection, 1, 159.

SKIRROW, M.B. (1977). Campylobacter enteritis: a "new" disease. British Medical Journal, $2,9$.

SKIRROW, M.B. \& BENJAMIN, J. (1980). Differentiation of enteropathogenic campylobacter. Journal of Clinical Pathology, 33, 1122.

SLEE, K.J. (1972). Human vibriosis an endogenous infection? Australian Journal of Medical Technology, 3, 7.
STEPHENSON, T.J. \& COTTON, D.W.K. (1985). Toxic megacolon complicating campylobacter colitis. British Medical Journal, 291, 1242.

TELFER BRUNTON, W.A. \& HEGGIE, D. (1977). Campylobacter-associated diarrhoea in Edinburgh (letter). British Medical Journal, 2, 956.

TURNBULL, P.C.B. \& ROSE, P. (1982). Campylobacter jejuni and salmonella in raw red meats: a Public Health Laboratory Service survey. Journal of Hygiene, Cambridge, 88, 29.

VERON, M. \& CHATELAIN, R. (1973). Taxonomic study of the genus Campylobacter Sebald and Veron and designation of the neotype strain from the type species, Campylobacter fetus (Smith and Taylor) Sebald and Veron. International Journal of Systemic Bacteriology, 23, 122.

VESELY, D., MACINTYRE, D.S. \& RATZAN, K.R. (1975). Bilateral deep vein thrombophlebitis due to Vibrio fetus. Archives of Internal Medicine, 135, 994.

VINZENT, R., DUMAS, J. \& PICARD, N. (1947). Septicemie grave au cours de la grossesse due a un vibrion: avortment consecutif. Bulletin de L'Academie National de Medecine (Paris), 131, 90.

WARREN, J.R. \& MARSHALL, B. (1983). Unidentified curved bacilli on gastric epithelium in active chronic gastritis. Lancet, i, 1273.

WILlOUGHBY, C.P., PIRIS, J. \& TRUELOVE, S.C. (1979). Campylobacter colitis. Journal of Clinical Pathology, 32 , 986. 